\title{
Refraction outcomes after suction loss during small-incision lenticule extraction (SMILE)
}

\author{
This article was published in the following Dove Press journal: \\ Clinical Ophthalmology \\ 13 March 2017 \\ Number of times this article has been viewed
}

\author{
Amr A Gab-Alla \\ Ophthalmology Department, Faculty \\ of Medicine, Suez Canal University, \\ Ismailia, Egypt
}

Purpose: To evaluate refractive outcomes of two management approaches after suction loss during the small-incision lenticule extraction (SMILE) technique.

Patients and methods: This retrospective and comparative study was conducted at the El-Gowhara Private Eye Center. It included 26 consecutive eyes of patients who experienced suction loss during the SMILE technique. Patients were divided into two groups by the technical difficulties in redocking: in group A (12 eyes) suction loss occurred after the posterior lenticular cut and the creation of side-cuts, then suction was reapplied, and the procedure was completed; in group B (14 eyes) suction loss occurred after the posterior lenticular cut and the creation of side-cuts, then the procedure was postponed for 24 hours and completed with the same parameters. Manifest refraction outcomes were measured and compared 6 months postoperatively.

Results: This study included 26 eyes with suction loss during the SMILE technique: five patients with suction loss in both eyes, nine patients with suction loss in the right eye and seven patients with suction loss in the left eye. The incidence of suction loss in this study was $2.7 \%$. At the postoperative 6-month follow-up time, there were statistically significant differences in refraction outcomes between the two groups, with a hyperopic shift in group A compared with group B.

Conclusion: A good refraction outcome can be achieved with appropriate management of suction loss during the SMILE technique, and it is recommended to postpone the treatment if this happens.

Keywords: diffuse lamellar keratitis, LASIK, interface fluid syndrome, myopia

\section{Introduction}

Small-incision lenticule extraction (SMILE) was carried out using the VisuMax femtosecond laser (Carl Zeiss Meditec AG, Jena, Germany), a femtosecond laser-based corneal refractive surgical procedure for myopia and myopic astigmatic correction. ${ }^{1,2}$

During the SMILE technique, after application of the topical anesthesia, standard sterile draping and insertion of eye speculum, the eye is centered onto the calibrated curved interface contact glass cone of the femtosecond laser. At the contact between this cone and the cornea, a meniscus tear film appears; at this point, the patient can clearly see the green fixation light. The surgeon instructs the patient to fixate directly on the green light, and once in position, the corneal suction is activated to fixate the eye in this position. Thus, the patient autocentrates the visual axis to the vertex of the contact glass, which is centered on the laser system and the center of the lenticule to be created. ${ }^{3}$

Then, the laser is activated for photo dissection in the following order. The posterior surface refractive lenticule is first created (using an out-to-in spiral direction of 
photo dissection), followed by the creation of side-cuts and then the anterior surface of the refractive lenticule (using an in-to-out spiral direction of photo dissection). The anterior surface of refractive lenticule extends beyond the posterior lenticule diameter by $0.5 \mathrm{~mm}$ to form the cap. Finally, a 2-3 mm tunnel incision is created that links the cap interface to the corneal surface. The total suction time average is $30-35$ seconds, according to the refractive state of the patient (the same cuts, but further apart for a higher refractive error). ${ }^{4}$

Then, the suction is released; the patient is moved to the surgical microscope of the laser machine for the lenticule separation and extraction. The small incision is opened by Seibel spatula (Rhein Medical, Inc., Saint Petersburg, FL, USA); the upper and lower surfaces of the lenticule are delineated. The upper interface is usually separated first, and then the lower interface is dissected. The lenticule is then removed by non-toothed forceps from the cornea. ${ }^{4}$

The SMILE technique is gaining reputation over laser in situ keratomileusis (LASIK) for several reasons. First, several studies ${ }^{2,3,5}$ have shown that the SMILE technique is efficient and safe, with a lower incidence of dry eye syndrome postoperatively. ${ }^{3}$ Moreover, SMILE is performed entirely using a femtosecond laser. The SMILE technique is a flapless procedure, which terminates flap-related complications and gives better corneal biomechanics than LASIK. ${ }^{6}$

The suction loss is an intraoperative complication that is common in the early learning curve of the SMILE technique for two reasons. First, it takes around 30-35 seconds for the femtosecond laser to complete the cuts (reduced to 25-28 seconds with a recent software update). Second, VisuMax laser is a low-pressure system, which increases the possibility of suction loss with longer duration of the procedure. ${ }^{5}$

The suction loss represents a management problem for refractive surgeons. Few reports have discussed the management of suction loss during the SMILE technique, ${ }^{5,7}$ and the ideal management of suction loss is deficient. This paper compares the refractive outcomes of two different management approaches of suction loss during the SMILE technique.

\section{Patients and methods}

This retrospective and comparative study was conducted at the El-Gowhara Private Eye Center. It included 26 consecutive eyes of patients who experienced the suction loss during the SMILE technique using the VisuMax $500 \mathrm{kHz}$ femtosecond laser system. The patients were divided into two groups: group A - suction loss occurred after the posterior lenticular cut and the creation of side-cuts; redocking was attempted quickly without difficulties, and the treatment was completed in the same session with the same parameters - and group B - suction loss occurred after the posterior lenticular cut and the creation of side-cuts; the procedure was postponed 24 hours due to technical difficulties in redocking, and completing the treatment. Those include the uncooperative patient with forcible lid squeezing, poor fixation of the patient to the green target light, fluid entrance between the suction ports of the interface cone due to chemosis of the conjunctivae and obscured the pupil of the patient by gas bubbles at the posterior lenticular cut. The entire treatment was repeated after 24 hours with the same parameters. All the patients in the two groups were treated by the same surgeon (AAG). Small patient interface cones were used in all patients ( $\mathrm{S}$ size). The manifest refraction outcomes of the two groups were recorded and compared. Patients were informed about the details and risks of the SMILE procedure, and all patients provided written informed consent for the procedure and inclusion in this study. The study was reviewed and approved by the institutional review board of Suez Canal University in agreement with the Declaration of Helsinki.

The eligibility criteria included spherical myopia up to -10 diopters and myopic astigmatism up to -4 diopters (manifest and cycloplegic refractions), a minimum age of 21 years, central corneal thickness $(\mathrm{CCT})>500 \mu \mathrm{m}$ at the thinnest point, the calculated residual stromal bed after treatment $>250 \mu \mathrm{m}$, a regular Sirius corneal topography (Scandicci, CSO, Italy) pattern and no other ocular conditions except myopia and astigmatism.

The cap thickness was set at $110 \pm 10 \mu \mathrm{m}$ (to ensure that the residual stromal bed was maintained $>250 \mu \mathrm{m}$ ) and exceeded the lenticule diameter by $1.0-2.0 \mathrm{~mm}$. The entering incision varied between 3 and $4 \mathrm{~mm}$ depending on the depth of the orbit and accessibility of the cornea. The size of the lenticule ranged from 6.0 to $7.0 \mathrm{~mm}$ with no transition zone for spherical errors and a $0.1 \mathrm{~mm}$ transition zone for astigmatism. The size of the lenticule was adjusted according to the mesopic pupil diameter of the patients. The minimum lenticule thickness at the edge was pre-set at $15 \mu \mathrm{m}$. The postoperative follow-up appointments were at the first day, first week, first month, third month and sixth month.

\section{Statistical analysis}

Data were coded, entered and analyzed using Microsoft Excel software. Data were then imported into the Statistical Package for the Social Sciences (SPSS; version 22.0, IBM, Armonk, NY, USA) software for analysis. Baseline data of the study population were presented as percentages and frequencies or mean values and standard deviations. The mean error in the treatment was calculated as the difference between preoperative and achieved postoperative spherical equivalent refraction 
at 6 months with a $P$-value (using the Mann-Whitney $U$ test for comparison between the groups and the Kruskal-Wallis $\mathrm{H}$ test to determine the statistically significant differences between multiple measures) of 0.05 .

\section{Results}

This study included 26 eyes with suction loss during SMILE technique: five patients with suction loss in both eyes, nine patients with suction loss in the right eye and seven patients with suction loss in the left eye. The incidence of suction loss in this study was $2.7 \%$ (26 of total 960 eyes). The patients were divided into two groups: group A (12 eyes) and group B (14 eyes); the demographic data of the two study groups are presented in Table 1.

Table 2 shows the preoperative characteristics of the two study groups. There were no statistically significant differences between the two groups; $P$-value $>0.05$.

The manifest refractions of the two study groups were recorded and compared at the postoperative first day, first week, first month, third month and sixth month (Table 3). Group A showed postoperative hyperopic refraction outcomes from the first postoperative day $(+1.78 \pm 0.52)$ up to the sixth month postoperatively $(+1.50 \pm 0.67)$. There was statistically non-significant mild improvement of the hyperopia up to the third postoperative month and stability of the refraction outcomes up to the sixth postoperative month $(P$-value $=0.775)$. Group B showed mild hyperopic refraction outcomes at the first postoperative day $(+0.43 \pm 0.28)$, which improved $(+0.25 \pm 0.32)$ at the sixth month postoperatively $(P$-value $=0.546)$.

At the postoperative 6 months follow-up time, there were statistically significant differences $(P$-value $=0.0001)$ in the manifest refraction outcomes between the two groups, with a hyperopic shift in group A compared with group B (Table 3). There were no any difficulties in tissue separation in both groups.

Table I Demographic data of the two study groups

\begin{tabular}{llll}
\hline $\begin{array}{l}\text { Demographic } \\
\text { data }\end{array}$ & $\begin{array}{l}\text { Group A } \\
(\mathbf{n}=12)\end{array}$ & $\begin{array}{l}\text { Group B } \\
(\mathbf{n}=1 \mathbf{1 4})\end{array}$ & P-value \\
\hline $\begin{array}{l}\text { Eye } \\
\quad \text { Right (n) }\end{array}$ & 5 & 9 & 0.25 \\
$\quad$ Left (n) & 7 & 5 & \\
$\begin{array}{l}\text { Sex } \\
\quad \text { Male, } n \text { (\%) }\end{array}$ & $5(41.7)$ & $4(28.6)$ & 0.68 \\
$\quad \begin{array}{l}\text { Female, } n(\%) \\
\text { Age (years) } \\
\quad \text { Mean } \pm \text { SD }\end{array}$ & $7(58.3)$ & $10(71.4)$ & \\
\hline
\end{tabular}

Notes: Group A, suction loss occurred after the posterior lenticular cut and the creation of side-cuts, then suction was reapplied, and the procedure was completed. Group B, suction loss occurred after the posterior lenticular cut and the creation of side-cuts, then the procedure was postponed for 24 hours and completed with the same parameters.

Abbreviation: SD, standard deviation.
Table 2 The preoperative characteristics of the two study groups

\begin{tabular}{llll}
\hline Preoperative characteristics & Group A & Group B & P-value \\
\hline Mean sphere equivalent (D) $\pm S D$ & $-5.00 \pm 2.8$ & $-4.3 \pm 1.7$ & 0.44 \\
Mean central corneal thickness & $563 \pm 40$ & $544 \pm 35$ & 0.21 \\
$(\mu \mathrm{m}) \pm S D$ & & & \\
Mean flat keratometry (D) $\pm S D$ & $43.2 \pm 1.8$ & $42.3 \pm 0.6$ & 0.09 \\
Mean steep keratometry (D) $\pm S D$ & $45.1 \pm 2.1$ & $45.3 \pm 1.3$ & 0.77 \\
Mean residual stromal thickness & $346 \pm 37.2$ & $355 \pm 26$ & 0.48
\end{tabular}

(mm) \pm SD

Notes: Group A, suction loss occurred after the posterior lenticular cut and the creation of side-cuts, then suction was reapplied, and the procedure was completed. Group B, suction loss occurred after the posterior lenticular cut and the creation of side-cuts, then the procedure was postponed for 24 hours and completed with the same parameters.

Abbreviation: SD, standard deviation.

\section{Discussion}

The SMILE technique was recently introduced as a single laser refractive procedure without the use of an excimer laser, ${ }^{4}$ in which a stromal lenticule is cut and extracted through a small arcuate incision using the femtosecond laser without creating a flap. ${ }^{8}$ Initial clinical results of the SMILE technique are hopeful, with reported postoperative refractive outcomes and fewer complications. ${ }^{9}$ It is now gaining worldwide acceptance and popularity. ${ }^{4}$

The suction loss during the SMILE technique is an intraoperative complication that can affect refraction outcomes negatively. The optimum management of this complication during refractive lenticule extraction remains uncertain. ${ }^{10}$

In this study, postoperative refraction outcomes of two groups with suction loss during the SMILE technique were recorded and compared with each other. In group A, it was possible to complete the surgical procedure by redocking and completing the technique, and in group B, the procedure was postponed for 24 hours and the same procedure was repeated. This study showed a hyperopic shift in group A compared with group B at the postoperative 6-month follow-up time.

Table 3 Postoperative manifest refraction outcomes of the two study groups

\begin{tabular}{llll}
\hline $\begin{array}{l}\text { Postoperative } \\
\text { follow up }\end{array}$ & $\begin{array}{l}\text { Group A } \\
(\text { mean } \pm \text { SD) }\end{array}$ & $\begin{array}{l}\text { Group B } \\
(\text { mean } \pm \text { SD) }\end{array}$ & $P$-value \\
\hline First day & $+1.78 \pm 0.52$ & $+0.43 \pm 0.28$ & $0.000 \mathrm{I}$ \\
First week & $+1.61 \pm 0.63$ & $+0.36 \pm 0.27$ & $0.000 \mathrm{I}$ \\
First month & $+1.52 \pm 0.60$ & $+0.29 \pm 0.44$ & $0.000 \mathrm{I}$ \\
Third month & $+1.50 \pm 0.67$ & $+0.25 \pm 0.32$ & $0.000 \mathrm{I}$ \\
Sixth month & $+1.50 \pm 0.67$ & $+0.25 \pm 0.32$ & $0.000 \mathrm{I}$ \\
P-value & 0.775 & 0.546 & \\
\hline
\end{tabular}

Notes: Group A, suction loss occurred after the posterior lenticular cut and the creation of side-cuts, then suction was reapplied, and the procedure was completed. Group B, suction loss occurred after the posterior lenticular cut and the creation of side-cuts, then the procedure was postponed for 24 hours and completed with the same parameters.

Abbreviation: SD, standard deviation. 


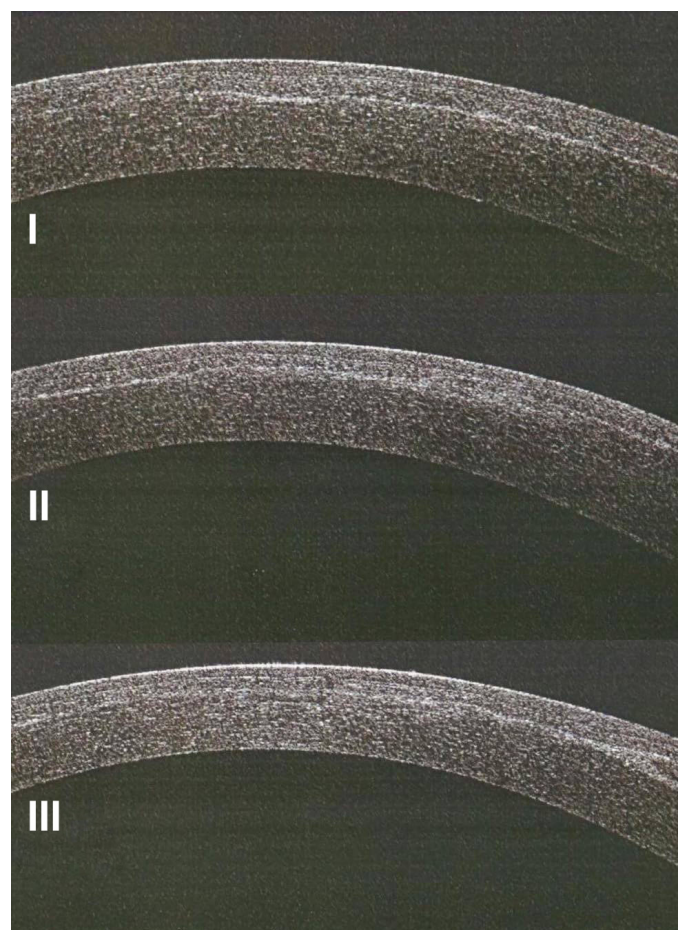

Figure I Postoperative anterior segment optical coherence tomography of the cornea of a group A patient shows a rough lamellar cut (I), an irregular interface (II), and the creation of two different dissection planes (III).

Notes: Group A, suction loss occurred after the posterior lenticular cut and the creation of side-cuts, then suction was reapplied, and the procedure was completed.

This can be explained as creating a second pass immediately after the suction loss might result in an uneven lamellar cut, an irregular interface, creation of two different dissection planes and more tissue squeezed with regained suction due to differences in applanation pressures (Figure 1). This might result in more tissue cutting and extraction and hyperopic shift postoperatively. However, with repetition of the procedure after 24 hours, there is enough time for the fluid and gas created to be absorbed before retreatment.

During the SMILE technique, low intraocular pressure $(\sim 35 \mathrm{mmHg})$ allows relatively good fixation during formation of the posterior lenticule cut, since the patient can see the green fixation light. However, this advantage is lost after the posterior lenticule is formed because vision is blurred, so more suction loss would likely occur during anterior lenticule formation. ${ }^{11}$

Osman et a ${ }^{12}$ investigated only the incidence and risk factors of suction loss during the SMILE technique for myopia or myopic astigmatism, and they did not discuss the refraction outcomes after the suction loss. They concluded that the rate of the suction loss could not entirely be explained by the learning curve, although surgical experience decreased suction loss but did not eliminate it.
Wong et $\mathrm{al}^{13}$ studied the incidence, management and outcomes of suction loss during the SMILE technique in 340 cases. They concluded that suction loss occurred in 11 eyes, eight $(72.7 \%)$ had an unaided visual acuity of $20 / 30$ or better and nine $(81.8 \%)$ had a spherical equivalent within \pm 0.5 diopters of emmetropia at 3 months. The suction loss occurred in four eyes during the posterior lenticular cut, in five eyes during the anterior lenticular cut, and in two eyes during the lamellar flap cut. In nine of these eyes, suction was reapplied at the same sitting, and the procedure was completed without further complications.

Smadja et al ${ }^{14}$ recommended not having a second pass on the same day if the suction is lost, especially in the central cornea. The possibility for an irregular interface, construction of two dissection planes due to differences in the applanation pressure, corneal hydration or conjunctival chemosis can affect the visual outcomes.

Muńoz et $\mathrm{al}^{15}$ evaluated visual acuity and refractive outcomes after myopic LASIK correction by Visx S2 (Visx Incorporated, Santa Clara, CA, USA) with uneventful single femtosecond laser pass versus double pass by IntraLase femtosecond laser after an intraoperative suction loss. At 12 months of follow-up, the refraction, uncorrected visual acuity and corrected visual acuity were measured. They concluded that a new femtosecond laser pass performed immediately after incomplete flap due to intraoperative suction loss provided good optical and visual outcomes. However, they used another femtosecond machine with femtosecond flap creation and treatment by LASIK, unlike the SMILE technique.

\section{Conclusion}

A good visual outcome can be achieved with appropriate management of the suction loss during the SMILE technique. It is recommended to postpone the treatment if this happens. Future developments in software will further decrease the risk for this complication.

\section{Disclosure}

The author reports no financial or proprietary interest in any material or method mentioned and no conflicts of interest in this work.

\section{References}

1. Sekundo W, Kunert K, Russmann C, et al. First efficacy and safety study of femtosecond lenticule extraction for the correction of myopia: six-month results. J Cataract Refract Surg. 2008;34(9):1513-1520.

2. Blum M, Kunert K, Schröder M, Sekundo W. Femtosecond lenticule extraction for the correction of myopia preliminary 6-month results. Graefes Arch Clin Exp Ophthalmol. 2010;248(7):1019-1027. 
3. Sekundo W, Kunert K, Blum M. Small incision corneal refractive surgery using the small incision lenticule extraction (SMILE) procedure for the correction of myopia and myopic astigmatism: results of a 6-month prospective study. Br J Ophthalmol. 2011;95(3):335-339.

4. Vestergaard A, Ivarsen AR, Asp S, et al. Small-incision lenticule extraction for moderate to high myopia: predictability, safety, and patient satisfaction. J Cataract Refract Surg. 2012;38(11):2003-2010.

5. Ang M, Chaurasia SS, Angunawela RI, et al. Femtosecond lenticule extraction (FLEx): clinical results, interface evaluation, and intraocular pressure variation. Invest Ophthalmol Vis Sci. 2012;53(3):1414-1421.

6. Reinstein DZ, Archer TJ, Randleman JB. Mathematical model to compare the relative tensile strength of the cornea after PRK, LASIK, and small incision lenticule extraction. J Refract Surg. 2013;29(7):454-460.

7. Sharma R, Vaddavalli PK. Implications and management of suction loss during refractive lenticule extraction (ReLEx). J Refract Surg. 2013; 29(7):502-503.

8. Blum M, Kunert KS, Engelbrecht C, et al. Femtosecond lenticule extraction (FLEx)-results after 12 months in myopic astigmatism. Klin Monatsbl Augenheilkd. 2010;227(12):961-965.

9. Wu D, Wang Y, Zhang L, et al. Corneal biomechanical effects: smallincision lenticule extraction versus femtosecond laser-assisted laser in situ keratomileusis. J Cataract Refract Surg. 2014;40(6):954-962.
10. Ivarsen A, Asp S, Hjortdal J. Safety and complications of more than 1500 small-incision lenticule extraction procedures. Ophthalmology. 2014;121(4):822-828.

11. Ang M, Mehta JS, Chan C, et al. Refractive lenticule extraction: transition and comparison of three surgical techniques. J Cataract Refract Surg. 2014;40(9):1415-1424.

12. Osman IM, Awad R, Shi W, Abou Shousha M. Suction loss during femtosecond laser-assisted small-incision lenticule extraction: incidence and analysis of risk factors. J Cataract Refract Surg. 2016;42(2): 246-250.

13. Wong CW, Chan C, Tan D, Mehta JS. Incidence and management of suction loss in refractive lenticule extraction. J Cataract Refract Surg. 2014;40(12):2002-2010.

14. Smadja D, Santhiago MR, Mello GR, Espana EM, Krueger RR. Suction loss during thin-flap Femto-LASIK: Management and beneficial refractive effect of the epithelium. J Cataract Refract Surg. 2012;38(5) 902-905.

15. Muńoz G, Albarr á n-Diego C, Ferrer-Blasco T, et al. Single versus double femtosecond laser pass for incomplete laser in situ keratomileusis flap in contralateral eyes: visual and optical outcome. J Cataract Refract Surg. 2012;38(1):8-15.
Clinical Ophthalmology

\section{Publish your work in this journal}

Clinical Ophthalmology is an international, peer-reviewed journa covering all subspecialties within ophthalmology. Key topics include: Optometry; Visual science; Pharmacology and drug therapy in eye diseases; Basic Sciences; Primary and Secondary eye care; Patient Safety and Quality of Care Improvements. This journal is indexed on

Submit your manuscript here: http://www.dovepress.com/clinical-ophthalmology-journal

\section{Dovepress}

PubMed Central and CAS, and is the official journal of The Society of Clinical Ophthalmology (SCO). The manuscript management system is completely online and includes a very quick and fair peer-review system, which is all easy to use. Visit http://www.dovepress.com/ testimonials.php to read real quotes from published authors. 